\title{
High latitude TEC fluctuations and irregularity oval during geomagnetic storms
}

\author{
I. I. Shagimuratov ${ }^{1}$, A. Krankowski ${ }^{2}$, I. Ephishov ${ }^{1}$, Yu. Cherniak ${ }^{1}$, P. Wielgosz ${ }^{2}$, and I. Zakharenkova ${ }^{1,2}$ \\ ${ }^{1}$ West Department of IZMIRAN, Kaliningrad, Russia \\ ${ }^{2}$ Geodynamics Research Laboratory, University of Warmia and Mazury, Olsztyn, Poland
}

(Received June 25, 2010; Revised August 1, 2011; Accepted October 8, 2011; Online published July 27, 2012)

\begin{abstract}
GPS measurements obtained by the global IGS network were used to study the occurrence of TEC fluctuations in the northern and southern high-latitude ionosphere during severe geomagnetic storms. In the northern hemisphere, GPS stations located higher than 55N Corrected Geomagnetic Latitude (CGL) at different longitudes were selected. In the southern hemisphere, Antarctic permanent GPS stations were used. Dual-frequency GPS measurements for individual satellite passes served as raw data. As a measure of fluctuation activity the rate of TEC (ROT) was used, and the fluctuation intensity was evaluated using the ROTI index. Using daily GPS measurements from all selected stations, images of the spatial and temporal behavior of TEC fluctuations were formed (in Corrected Geomagnetic Coordinates-CGC and geomagnetic local time-GLT). Similarly to the auroral oval, these images demonstrate an irregularity oval. The occurrence of the irregularity oval relates to the auroral oval, cusp and polar cap. During a storm, the intensity of TEC fluctuations essentially increased. The irregularity oval expands equatorward with an increase of magnetic activity. The study showed that the existing high-latitude GPS stations can provide a permanent monitoring tool for the irregularity oval in near real-time. In this paper, the features of the development of phase fluctuations at the geomagnetic conjugate points, and inter-hemispheric differences and similarities during winter and summer conditions, are discussed.
\end{abstract}

Key words: GPS, TEC fluctuations, modeling of ionosphere, polar cap patches.

\section{Introduction}

It is known that GPS radio signals passing through the ionosphere suffer varying degrees of rapid variations of their amplitude and phase-signal scintillations. The scintillations are caused by the presence of a wide range of scale size irregularities in the ionosphere. The amplitude scintillations come from irregularities having a scale size of the first Fresnel zone $R=\sqrt{\lambda z}$, which depends on the signal wavelength $(\lambda)$ and average height of the irregularity layer $(z)$. For the GPS, this scale works out to be $370-$ $400 \mathrm{~m}$. Phase scintillations at frequencies much lower than the Fresnel frequency are caused by irregularities with scale sizes that are much larger than the size of the first Fresnel zone. Under such conditions, refraction effects can be taken into account and the phase fluctuations are due to the optical path changes of a radio wave (Pi et al., 1997). The low-frequency GPS phase fluctuations may be directly due to electron density changes along the radio ray path (or the total electron content (TEC) changes). Standard GPS observations, with a $30 \mathrm{~s}$ sampling, provide measurements of the irregularities at high latitudes with a scale size of the order of $>30 \mathrm{~km}$. Effects of ionospheric irregularities on the GPS signals can be evaluated by measurements of the differential phase time rate of dual frequency (1.2 and 1.6

Copyright (C) The Society of Geomagnetism and Earth, Planetary and Space Sciences (SGEPSS); The Seismological Society of Japan; The Volcanological Society of Japan; The Geodetic Society of Japan; The Japanese Society for Planetary Sciences; TERRAPUB.

doi:10.5047/eps.2011.10.015
GHz) GPS signals (Aarons, 1997).

In recent years, the interest of the scientific community in studying ionospheric irregularities has increased. Smallscale irregularities produce amplitude and phase scintillation, which can degrade transionospheric signals and can influence the performance of space communication radio systems (Forte and Radicella, 2004; Stankov and Jakowski, 2007; Rama Rao et al., 2009). It is very important to estimate scintillation and phase fluctuation effects on the GNSS navigation system (GPS/GLONASS) performance and, consequently, on the precession of the obtained position. Large-scale irregularities, and associated TEC fluctuations, can complicate phase ambiguity resolution, increase the number of undetected and uncorrected cycle slips and losses of signal lock in GNSS (Wanninger, 1995; Jakowski et al., 2005; Wielgosz et al., 2005).

Currently, there is a high demand to increase the precision and reliability of GPS positioning. The morphology and spatial and temporary dynamics of phase fluctuations depends on geophysical conditions, and a knowledge of these is very important, especially during geomagnetic storms. The GPS technique is well suited to study TEC fluctuations on a global scale and on a regular basis, because the international network of GPS permanent stations is very broad and dense.

In a previous study, Shagimuratov et al. (2009) reported differences in the occurrence of GPS phase fluctuations during a geomagnetic storm in the Northern and Southern hemispheres. In this paper, extended and more detailed 
Table 1. List of stations whose data are used in Sections 4, 5 and 6.

\begin{tabular}{|c|r|r|r|c|}
\hline \multirow{2}{*}{ Stations } & \multicolumn{2}{|c|}{ Geographic coordinates } & \multicolumn{2}{c|}{$\begin{array}{c}\text { Corrected geomagnetic } \\
\text { coordinates }\end{array}$} \\
\cline { 2 - 5 } & latitude & longitude & latitude & longitude \\
\hline MCM4 & -77.50 & 166.40 & -79.99 & 322.95 \\
RESO & 74.41 & -94.53 & 83.10 & 320.28 \\
MAC1 & -54.30 & 158.56 & -64.18 & 247.29 \\
FAIR & 64.58 & -147.30 & 64.95 & 264.67 \\
WHIT & 60.45 & -135.13 & 63.29 & 278.64 \\
KERG & -49.21 & 70.15 & -58.29 & 123.33 \\
JOEN & 62.23 & 30.05 & 58.36 & 108.44 \\
DAV1 & -68.34 & 77.58 & -74.67 & 102.29 \\
NYAL & 78.55 & 11.52 & 75.77 & 111.78 \\
\hline
\end{tabular}

analyses of the development of TEC fluctuations in both the Northern and Southern hemisphere are presented. In addition, winter and summer events (November and July 2004 storms) were compared. In this report, special attention is given to the features of the occurrence of TEC fluctuations in both hemispheres for conjugate GPS stations.

GPS measurements of the selected stations have enabled a study of the differences, and similarities, of the occurrence of TEC fluctuations over the Northern and Southern hemispheres. The comprehensive image of TEC fluctuations and ionospheric irregularities was obtained using multi-station GPS measurements collected at stations located higher than $50^{\circ}$ Corrected Geomagnetic Latitudes (CGL) that monitor the polar, auroral and subauroral ionosphere.

\section{Data}

GPS observations carried out at the Antarctic and Arctic IGS (International GNSS Service) stations were used to study the development of TEC fluctuations in the highlatitude ionosphere. Standard GPS measurements, with a 30 s sampling rate, allow the detection of middle- and largescale ionospheric irregularities.

The dynamics of the high-latitude ionosphere is controlled by the geomagnetic field. In the polar ionosphere, the physical processes have similar effects in both hemispheres, especially concerning the magnetic conjugate areas.

For a correct comparison of the development of TEC fluctuations, GPS stations with closely-related geomagnetic coordinates were selected. Table 1 presents the geographic and Corrected Geomagnetic Coordinates (CGC) of the conjugate stations analysed in this paper. For the analysis of TEC fluctuations, high-precision dual-frequency GPS phase-measurements of individual satellite passes were used. As a measure of phase fluctuation activity, the rate of TEC (ROT) in units of TECU/min was used, where $1 \mathrm{TECU}=10^{16}$ electron $/ \mathrm{m}^{2}$. Using ROT for the analyses avoids the problem of unknown phase ambiguities (Wanninger, 1995):

$$
\mathrm{ROT}=9.53\left(\left(\Phi_{1}-\Phi_{2}\right)_{t_{j}}-\left(\Phi_{1}-\Phi_{2}\right)_{t_{i}}\right)
$$

$\Delta t=t_{j}-t_{i}=1 \mathrm{~min}, \Phi_{1}$ and $\Phi_{2}[\mathrm{~m}]$ denote the measured differential carrier phase observed at $L_{1}$ and $L_{2}$. A scaling factor converts the differential ionospheric delay to TECU.
The Rate of TEC Index (ROTI), based on standard deviations of ROT, was used for the analyses of the intensity of the TEC fluctuations (Shagimuratov et al., 2009). The indices computed only from observations at elevation angles higher than $20^{\circ}$ are considered. Scintillation indices are projected onto the vertical direction, in order to account for varying geometrical effects affecting the measurements made at different elevation angles. When mapping the slant TEC to the vertical one, we use an ionospheric height of $450 \mathrm{~km}$.

GPS observations of the Northern hemisphere provided raw data for mapping the irregularities over the North Pole. GPS data from over 40 GPS stations located in the longitudinal sector $65^{\circ} \mathrm{W}-25^{\circ} \mathrm{E}$ and $50^{\circ} \mathrm{N}-83^{\circ} \mathrm{N}$ geographic coordinates provided a detailed spatial structure and reveal the TEC fluctuations for different geomagnetic conditions.

\section{Geomagnetic Conditions}

In Fig. 1, geomagnetic conditions for July and November, 2004 , storms are presented. The main phase of both storms started before midnight (UT $=00$ ) on July 22-23 and November 6-7, respectively. $D_{\text {st }}$ index reached $-190 \mathrm{nT}$ on July 27 , and 370 nT on November 8 , respectively. The maximum sum of $K_{\mathrm{p}}$ reached $61-$ on July 27 , and $56+$ on November 10. The temporal development of both storms was rather similar.

\section{Development of TEC Fluctuations during July 2004 Storm}

\subsection{Polar GPS stations}

The strongest TEC fluctuations have been usually registered in the polar ionosphere. Krankowski et al. (2005) have shown that, at polar stations, TEC fluctuations occurred as short-term TEC enhancements of a factor of 2-5 relative to quiet time. The TEC fluctuations were associated with polar cap patches. These are large regions of enhanced $F$ region plasma density. The patches travel through the ionospheric polar caps under the influence of high-latitude convection (Weber et al., 1984; Pedersen et al., 2000). Patches are typically considered to be of the order of 100-1000 km in the horizontal plane. The first observations of patch structures with a GPS technique were presented by Weber et al. (1986). The travelling speed of the patch is between 300$900 \mathrm{~m} \mathrm{~s}^{-1}$ (Rodger and Rosenberg, 1999). Thus, the duration of occurrence of the patches can exceed 10 minutes or 

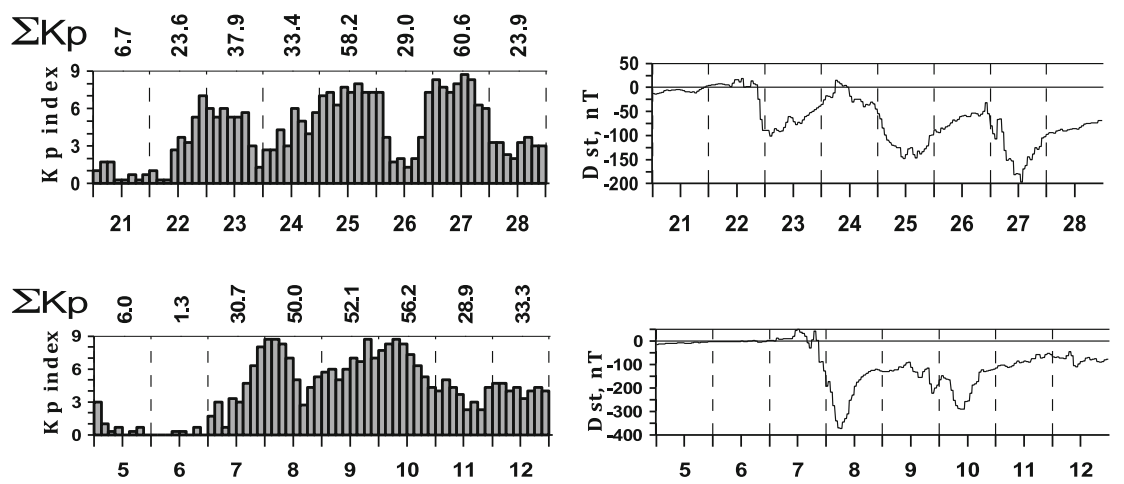

Fig. 1. $K_{\mathrm{p}}$ and $D_{\mathrm{st}}$ variations during July 21-28 (top) and November 5-12, 2004 (bottom).
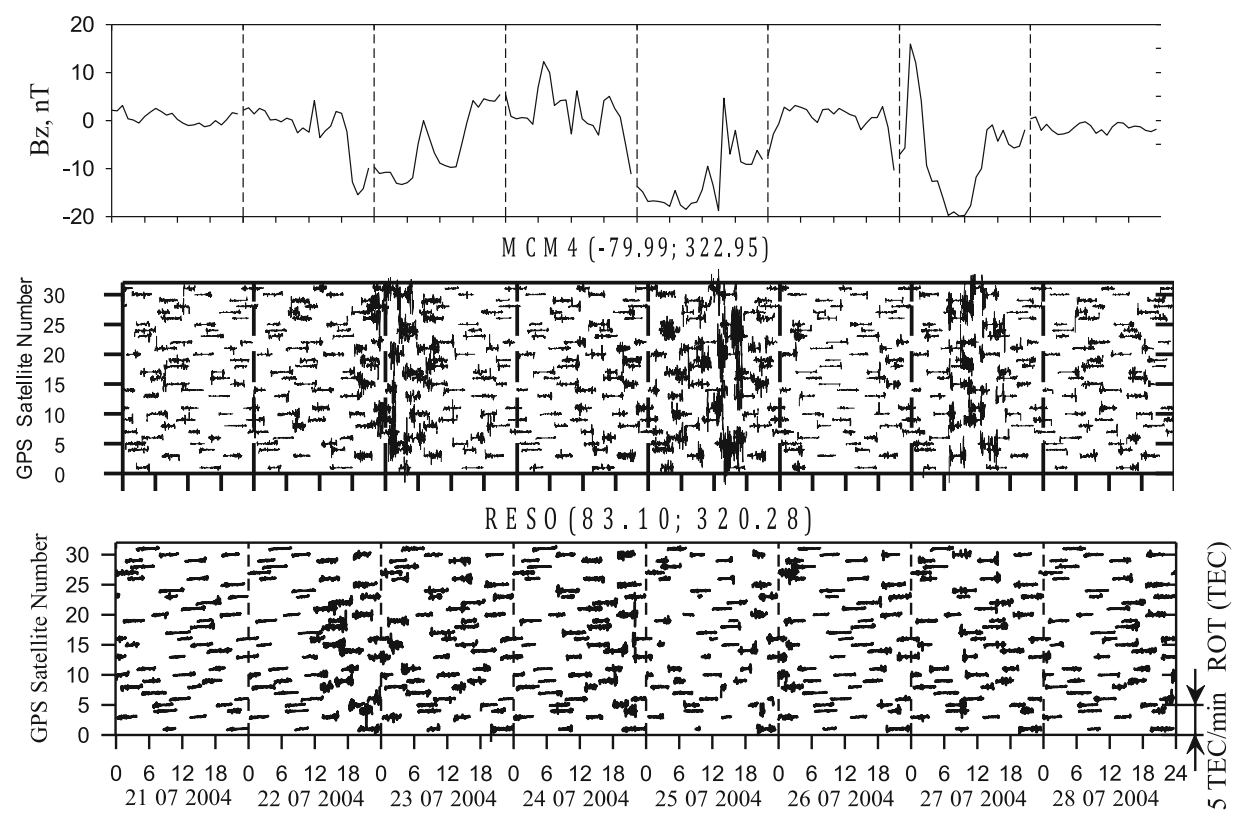

Fig. 2. Development of TEC fluctuations at polar stations and IMF $B_{z}$ variations during July 21-28, 2004. The figure shows the time rate change of TEC (TECU/min) along satellite passes over an individual station (ROT). Separation between satellites is 5 TECU.

more.

The occurrence of TEC fluctuations was analysed using ROT along individual stations. Figure 2 presents the development of TEC fluctuations during the geomagnetic activity period of July 23-27, 2004. The figures illustrate the occurrence of TEC fluctuations for all passes of the satellites observed at the Southern and Northern hemispheres over a 24-hour interval on quiet and disturbed days. Figure 2 also presents variations of the $B_{z}$ component of the interplanetary magnetic field (IMF) during the period discussed.

Figure 2 demonstrates the development of TEC fluctuations at the polar MCM4 and RESO magnetic conjugate stations. This pair of stations is located within the polar cap during quiet conditions. In such conditions weak fluctuations were observed in the polar ionosphere in different azimuths. During July 24 and 27, when $B_{z}$ varied around zero, weak and moderate fluctuations at both stations were observed. The behaviour of TEC fluctuations at conjugated areas for all satellite passes was similar. As seen in the figures, the IMF $B_{z}$ component exhibits some shift to the South. At first, $B_{z}$ turned to the South (negative $B_{z}$ ) on July
22, 2004 and reached the maximal value of about $15 \mathrm{nT}$ around 18 UT, and remained high until 06 UT July 23, 2004. At the same time, strong TEC fluctuations were developed over the MCM4 station. The next period of negative $B_{z}$ took place on July 25, 2004, and lasted more than 15 hours. This time, the fluctuation intensity also sharply increased over the MCM4 station. A similar situation was observed during July 27, 2004, when $B_{z}$ reached an extreme value of more than $20 \mathrm{nT}$. On the other hand, this effect was less pronounced at the northern station RESO. Such an occurrence of TEC fluctuations may appear to be related with other effects. The MCM4 station is located closer to the geographic pole than RESO. Taking into account the inclination of GPS orbits, the satellites at the MCM4 station are usually observed at lower elevation angles than at the station RESO. In order to reduce this factor, satellites with elevations over $20^{\circ}$ were used. Figure 3 shows that the difference in satellite elevation angles between these stations is not essential.

Differences of TEC fluctuations on the conjugate points may also be caused by the location of stations within high- 

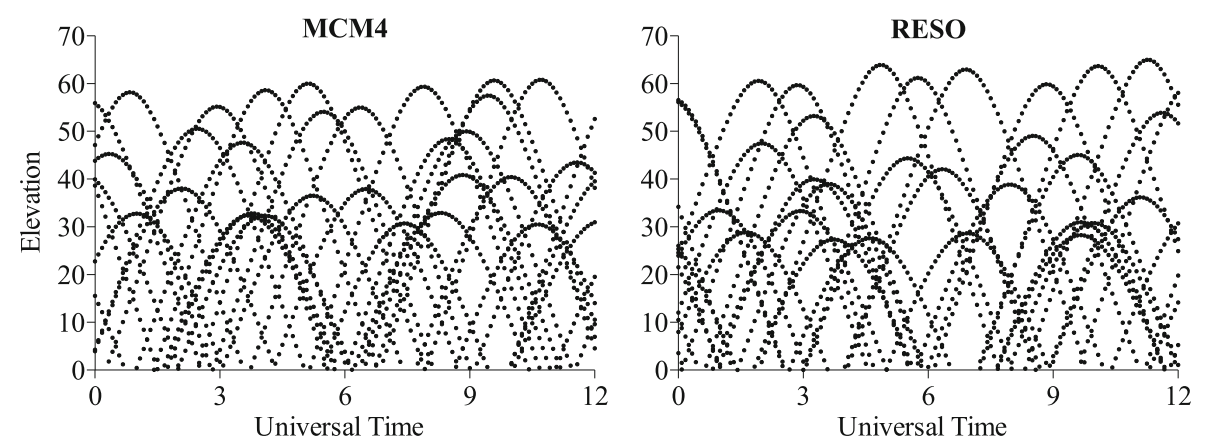

Fig. 3. Elevations of GPS satellites over MCM4 and RESO during 12-hour interval.

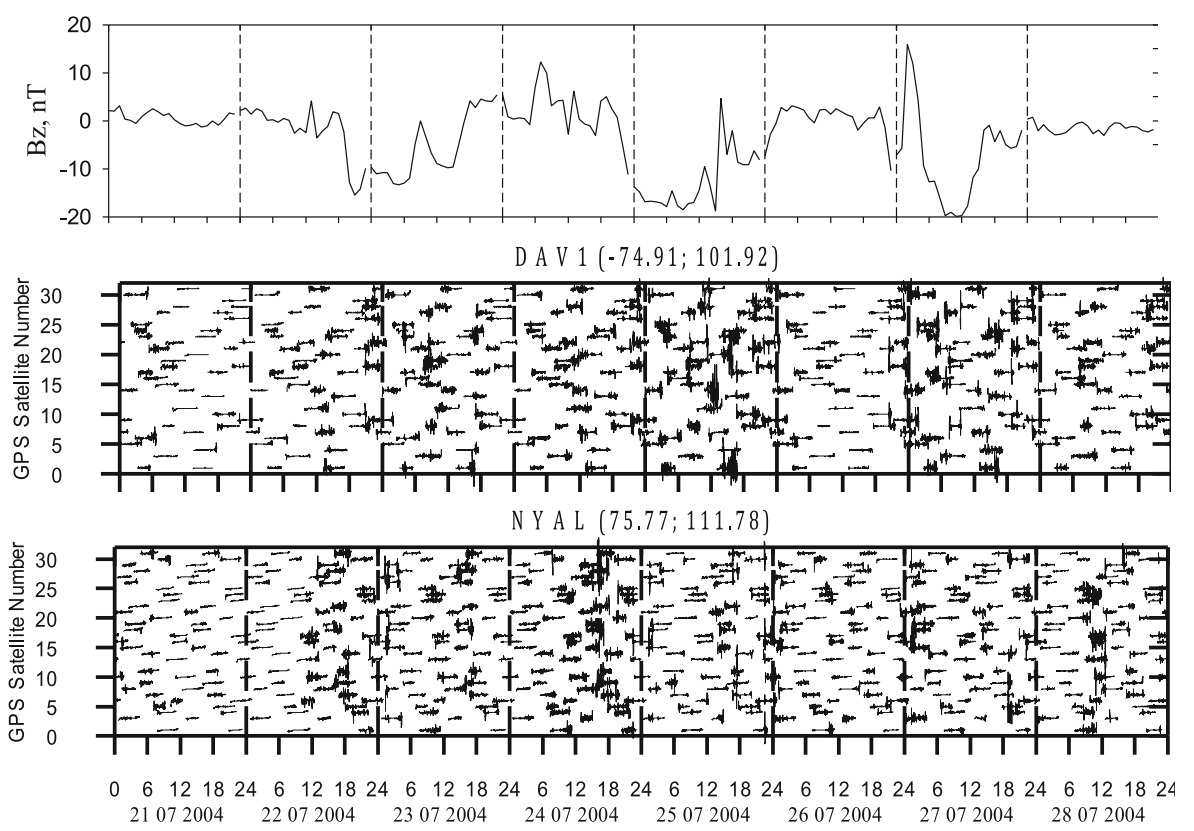

Fig. 4. Development of TEC fluctuations at stations located near the poleward edge of the auroral oval and IMF $B_{z}$ variations during July 21-28, 2004.

latitude geophysical structures (cusp, polar cap). The RESO station is located at a higher geomagnetic latitude than the MCM4 station, so, during the disturbances, RESO may be located in the cusp area and MCM4 in the polar cap. The location of these structures varies and depends on the geomagnetic conditions. It is probable that the difference in the occurrence of TEC fluctuations in both hemispheres has seasonal effects.

\subsection{Auroral stations}

Figure 4 shows the fluctuation occurrence over DAV1 and NYAL stations located near the poleward edge of the auroral oval. The behaviour of the fluctuation at both stations is rather similar. The TEC fluctuations were observed even in the quiet period (as at the polar stations). During the most disturbed day, the intensity of fluctuations increased and was invariable during the entire day. The development of the TEC fluctuation over the auroral stations is also controlled by the behaviour of $B_{z}$, and the fluctuations were maximal when $B_{z}$ was negative. At the same time, at the NYAL station, TEC fluctuations were very well expressed when $B_{z}$ sharply changed its sign. During disturbances, the fluctuation activity was much higher at the southern station DAV1 than at NYAL.
Figure 5 presents TEC fluctuations over the magnetic conjugate stations MAC1, FAIR and WHIT, which, in quiet geomagnetic conditions, are located at the equatorward wall of the auroral oval. Day-by-day development of TEC fluctuations at these stations shows some similarities. During the disturbed days, when $B_{z}$ was negative, strong fluctuations prevailed. It is interesting that during July 24, 2004, while the $B_{z}$-component varied around zero, moderate TEC fluctuations were registered at the FAIR station. The fluctuation activity was more clearly expressed also at polar stations in the Southern hemisphere. The difference in the occurrence of TEC fluctuations in both hemispheres has seasonal effects.

\subsection{Subauroral stations}

At the subauroral stations KERG and JOEN (Fig. 6) fluctuations were observed during most of the disturbed days, when $B_{z}$ was negative. The behaviour of TEC fluctuations in both hemispheres was very similar. It is interesting that when disturbed conditions remained $\left(\Sigma K_{\mathrm{p}} 30-35\right)$ at the subauroral stations, the TEC fluctuation activity was low. There is a high correlation between the occurrence of TEC fluctuations and variations of the $D_{\mathrm{st}}$ index. The TEC fluctuations took place when the $D_{\text {st }}$ index sharply decreased. 

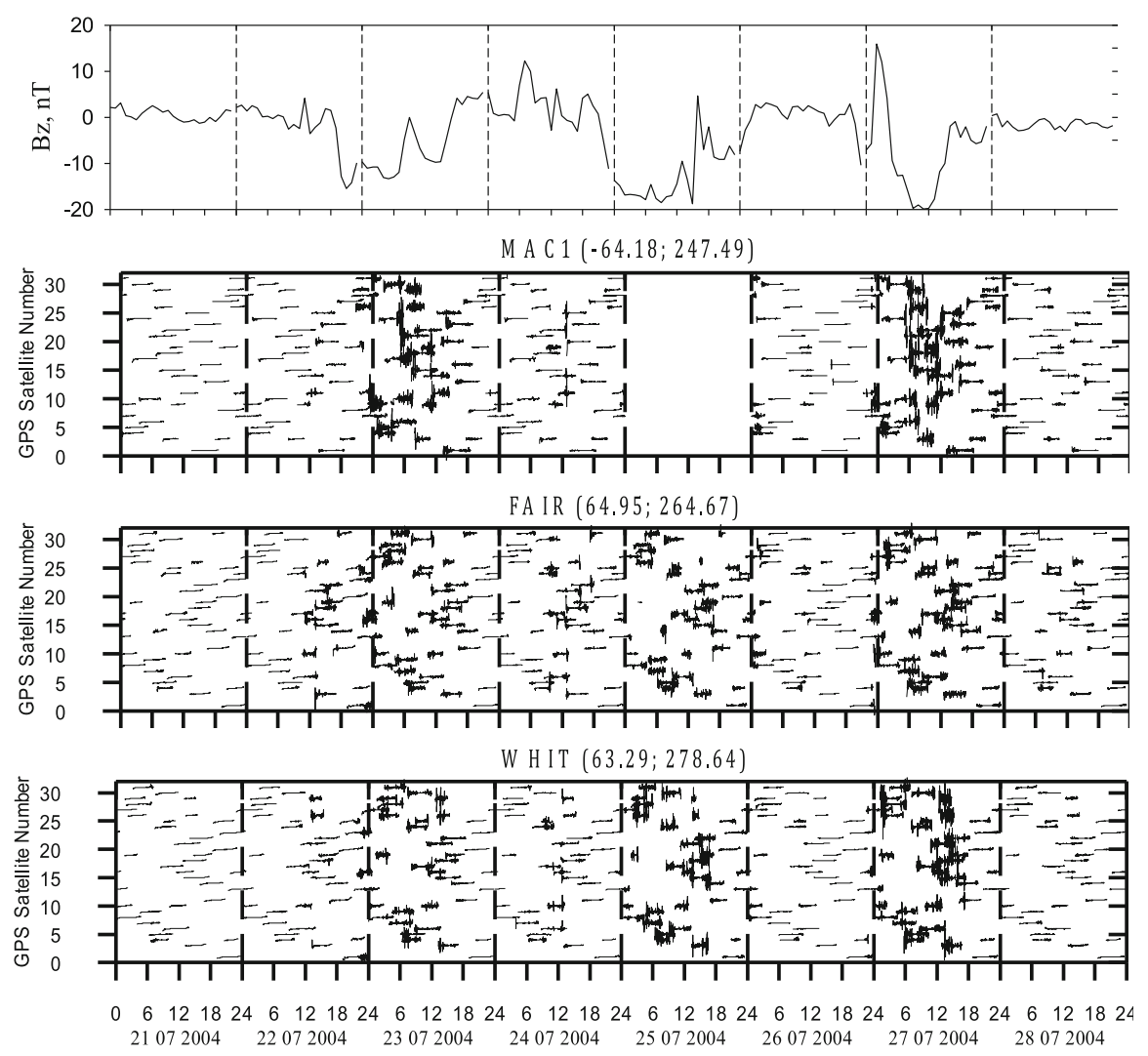

Fig. 5. Development of TEC fluctuations at stations located near the equatorward edge of the auroral oval and IMF $B_{z}$ variations during July $21-28$, 2004. Gaps in the data were caused by a lack of observations.

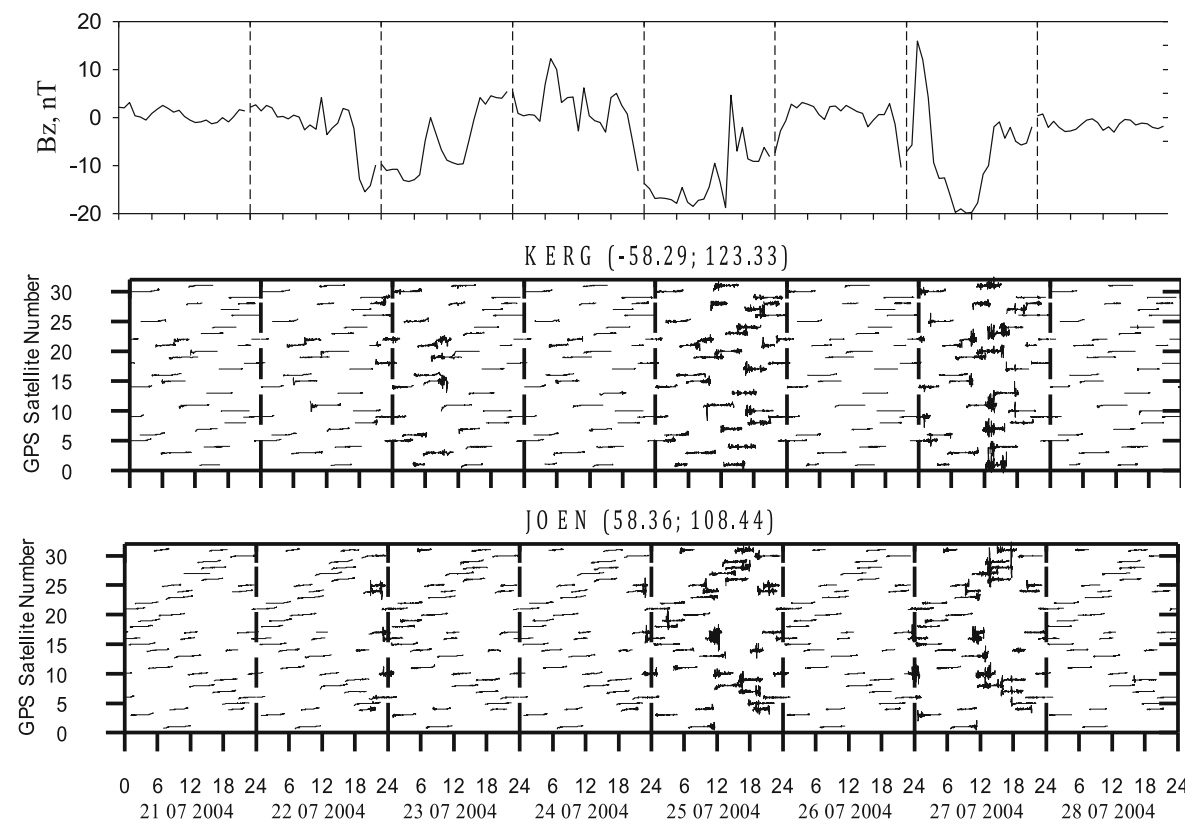

Fig. 6. Development of TEC fluctuations at subauroral stations and IMF $B_{z}$ variations during July 21-28, 2004.

The analysis shows that when fluctuations were developed in the subauroral ionosphere, the ionospheric trough moved to lower latitudes of $50-55^{\circ} \mathrm{N}$. It is known that near the walls of the trough, where strong gradients are present, different scale irregularities can be observed. They are caused by the increasing TEC fluctuation activity.

\section{Development of TEC Fluctuations during November 2004 Storm}

The November 2004 storm started near the same UT time as the July 2004 storm, but it exhibited two active phases (see Fig. 1). Figure 7 presents a development of the storm in TEC fluctuations (ROT) at the same conjugate stations as for the July 2004 storm. In contrast to the July storms, 


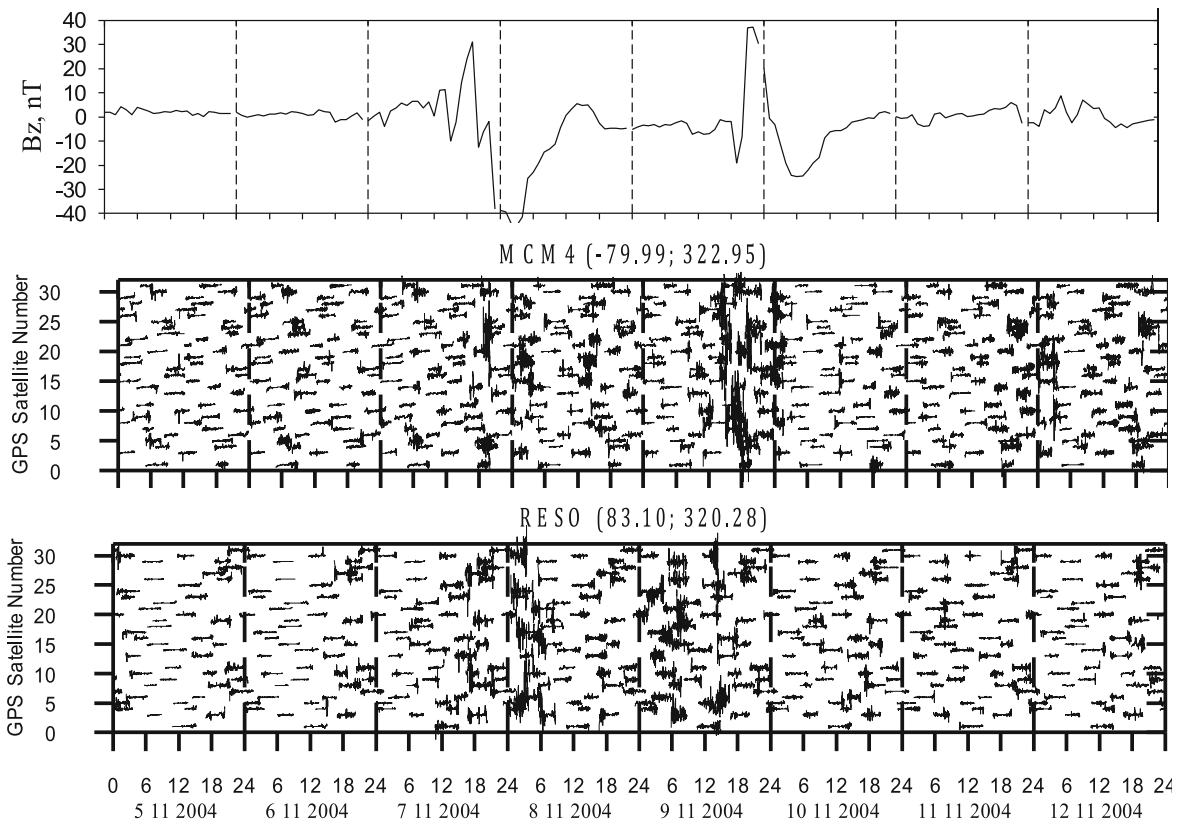

Fig. 7. Development of TEC fluctuations at polar stations and IMF $B_{z}$ variations during November 5-12, 2004.
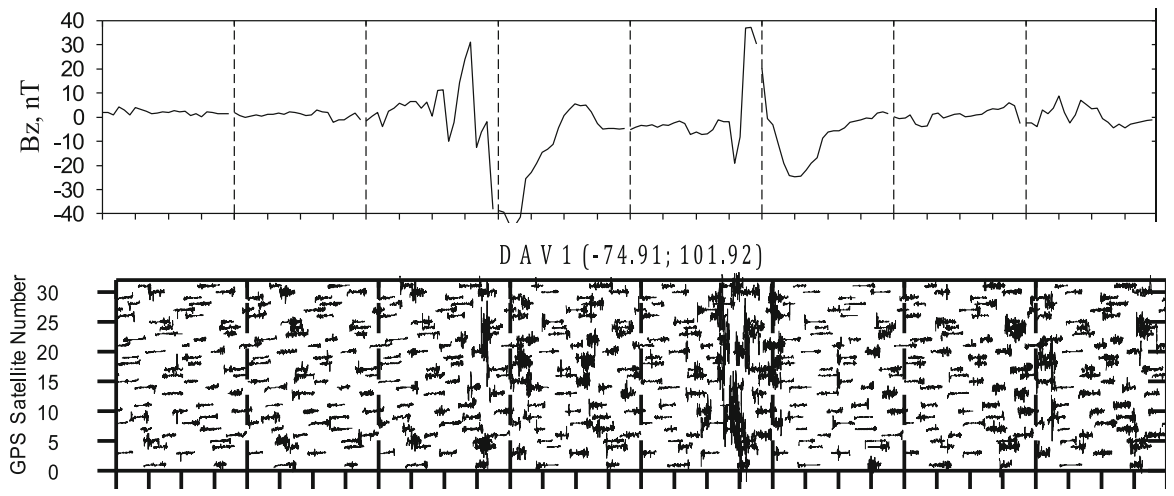

N Y A L $(75.77 ; 111.78)$

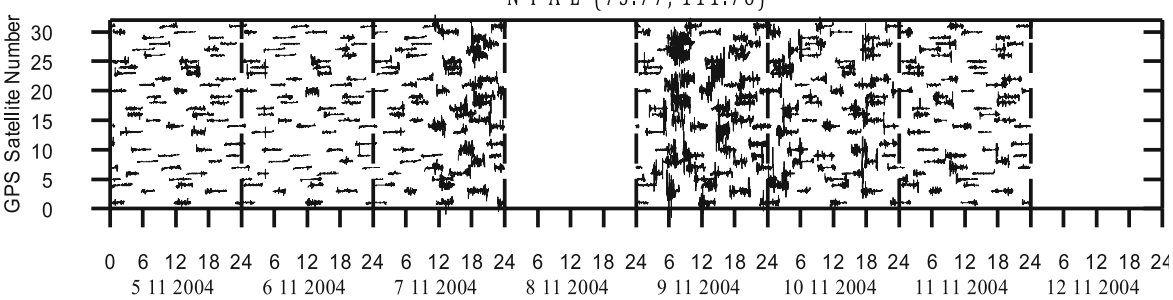

Fig. 8. Development of TEC fluctuations at stations located near the poleward edge of the auroral oval and IMF $B_{z}$ variations during November 5-12, 2004. Gaps in the data were caused by a lack of observations.

the differences between the northern (RESO), and southern (MCM4), polar stations are less pronounced. Development of TEC fluctuations at both stations began after $18 \mathrm{UT}$, when $B_{z}$ dramatically increased to $+30 \mathrm{nT}$ for a short period and then sharply fell to $-45 \mathrm{nT}$. The intensity of the fluctuations in winter (at RESO) during this period were slightly stronger than in summer (at MCM4). In contrast, after $18 \mathrm{UT}$ on November 7 , when $B_{z}$ also sharply reached $+35 \mathrm{nT}$ and remained on that level for $\sim 1.5$ hours, strong TEC fluctuations took place at MCM4 (in the summer ionosphere). It is very interesting that, in the winter ionosphere, strong TEC fluctuations were observed throughout on November 9, 2004. At this time, the substorm activity was developed and $\Sigma K_{\mathrm{p}}$ reached $52^{\circ}$.

At the high-latitude auroral station NYAL (Fig. 8) in the winter ionosphere, strong fluctuations were observed during the storm period, with maximal effect taking place on November $7\left(\Sigma K_{\mathrm{p}}=32-\right)$ and November $9\left(\Sigma K_{\mathrm{p}}=\right.$ $52^{\circ}$ ), during the main phases of the two storms. It should be noted that, at the same time, strong fluctuations were detected when $B_{z}$ was both negative and positive. In the summer ionosphere, at DAV1 station, the intensity of TEC fluctuations (see Fig. 10) was weaker at DAV1 station in contrast to the winter (NYAL station).

The analysis of the storm shows that at the subauroral conjugated stations JOEN and KERG (Fig. 9) TEC fluc- 

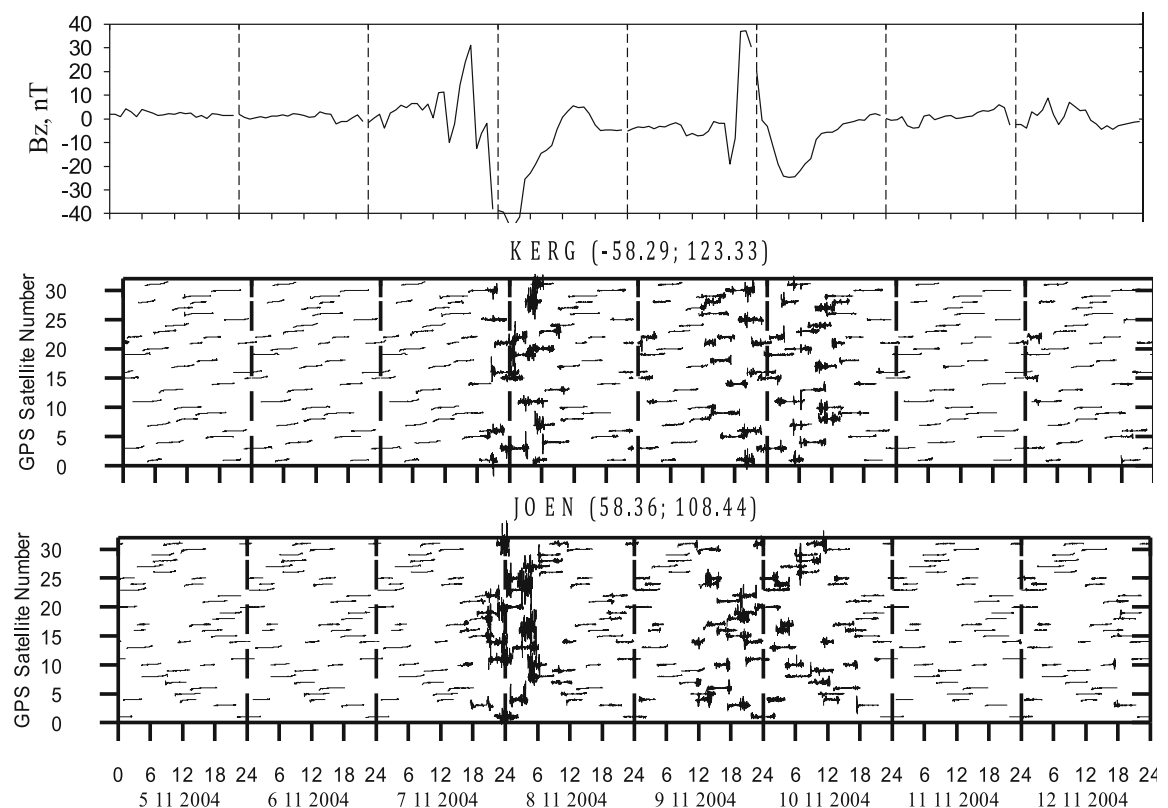

Fig. 9. Development of TEC fluctuations at subauroral stations and IMF $B_{z}$ variations during November 5-12, 2004.

tuations took place on November 7-8 and 9-10, and the appearance of these fluctuations was similar. However, on November 8 the fluctuations at the northern station JOEN were more clearly expressed than at the southern KERG station. The strongest fluctuations were observed when $B_{z}$ was maximal negative or positive.

\section{Temporal and Spatial Occurrence of TEC Fluc- tuations}

TEC fluctuations, and also phase fluctuations, are caused by the presence of medium- and small-scale irregularities in the ionosphere. In order to estimate the TEC fluctuations, dual-frequency phase measurements with a $30 \mathrm{~s}$ interval have been used. A ROT parameter with a 1-minute interval was used to estimate phase fluctuations. As a measure of the ionospheric activity, ROTI was also used. ROTI was estimated at a 10-minute interval.

$$
\text { ROTI }=\sqrt{\left\langle\text { ROT }^{2}\right\rangle-\langle\text { ROT }\rangle^{2}} .
$$

Similarly to the results presented above, the spatial and temporal occurrence of the irregularities can be graphically presented in magnetic local time (MLT) and Corrected geomagnetic latitude (CGL) coordinate system. As an example, Figs. 10 and 11 show the location of TEC fluctuations derived from GPS measurements in GLT and CGL over different conjugate stations during quiet (July 21 and November 6, 2004) and disturbed (July 27 and November 8, 2004) days for the events under consideration. The intensity of the fluctuations is indicated with different symbols.

It can be seen that during quiet days at the polar stations (MCM4/RESO) weak and moderate TEC fluctuations were observed all day. MCM4 station probed the ionosphere covering latitudes in the range of $<80^{\circ}$ and the RESO station $>80^{\circ}$, because the magnetic latitude of RESO station is higher than that of MCM4 station. During disturbed days the intensity of TEC fluctuations essentially increased.
Maximal intensity occurred temporally while the $B_{z}$ component of IMF was strong. Figure 10 shows that the intensity of TEC fluctuations in winter was higher than in summer.

In the high-latitude auroral ionosphere the over DAV1/NYAL stations the intensity of fluctuations was lower than over the polar stations. At these stations, the intensity of the fluctuations increased during the disturbances, similarly to the polar ionosphere. The seasonal effect also was observed, the intensity of fluctuations was higher in winter than in summer. During quiet geomagnetic conditions at the subauroral stations KERG/JOEN, the intensity of the TEC fluctuations was very low (less than $0.01 \mathrm{TECU} / \mathrm{min}$ ). This effect is clearly visible in the figures. During disturbed days, however, the intensity of the TEC fluctuations essentially increased. Maximal effect took place when the $B_{z}$ component had high values. The seasonal effect was similar to the auroral ionosphere.

\section{Oval of Irregularities}

In order to obtain a comprehensive picture of the spatial distribution of ionospheric irregularities in the high-latitude ionosphere, GPS data covering the subauroral, auroral and polar ionosphere are required. Over recent years, the number of high-latitude GPS stations has been increased. The Greenland network of GPS stations is located within the latitudinal range of $87-63^{\circ} \mathrm{CGL}$ and the distances between the stations are $<0.5^{\circ}$. More than 40 Greenland stations were used to form an image of the latitudinal structure of TEC fluctuations over the Northern hemisphere. To determine the subauroral ionosphere, GPS observations from lowerlatitude stations close to Greenland were added. For all satellite passes over individual stations, the intensity index of TEC fluctuations (ROTI) with a 10-min interval in corrected geomagnetic coordinates of subionospheric points, as well as MLT, have been calculated. Using the data from a total of over 60 GPS stations, the day by day images of 

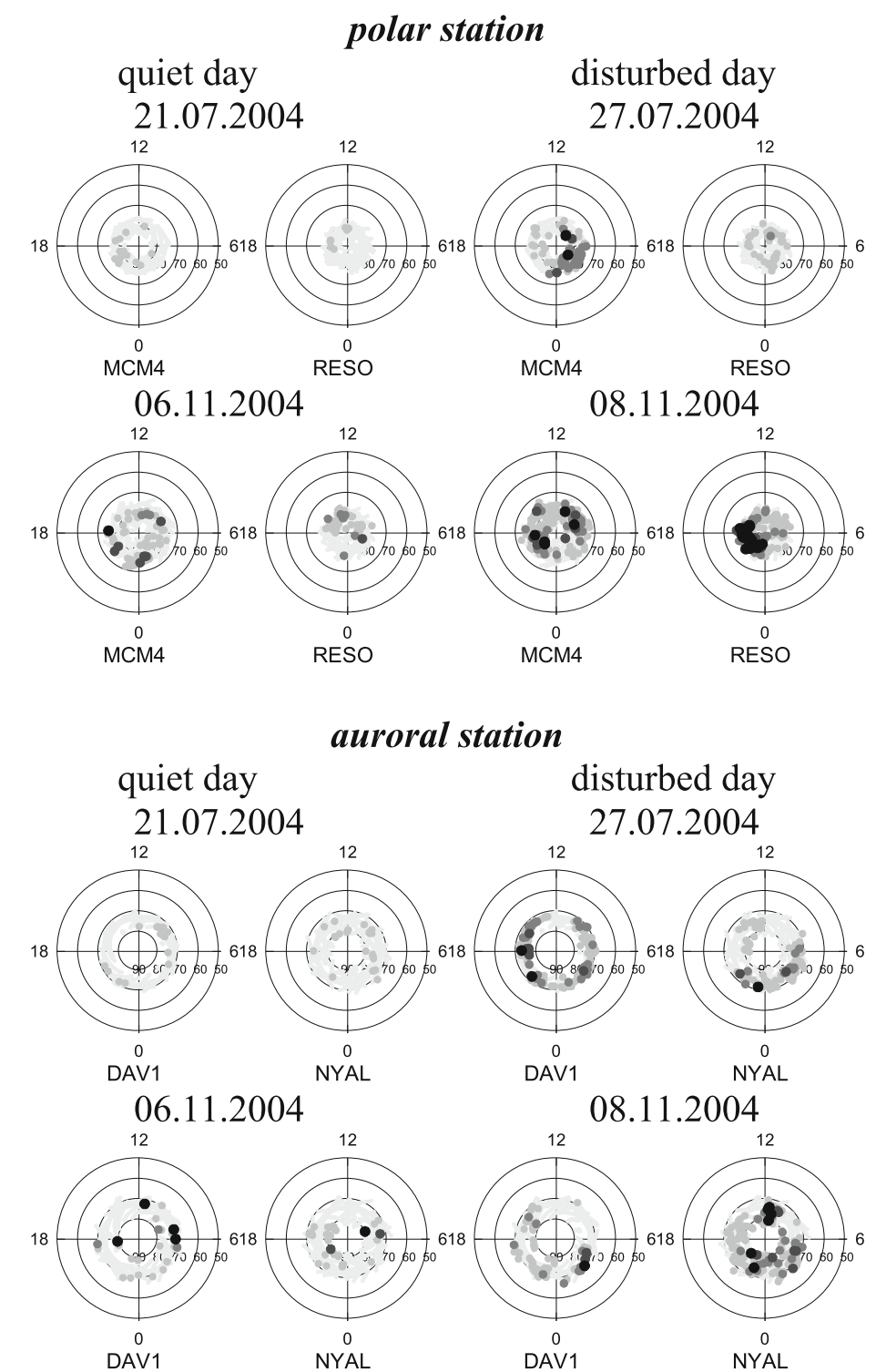

\section{subauroral station}

quiet day

disturbed day

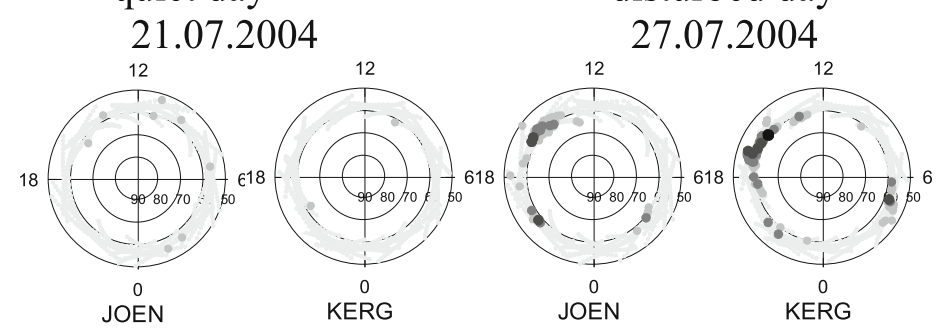

06.11 .2004

08.11.2004

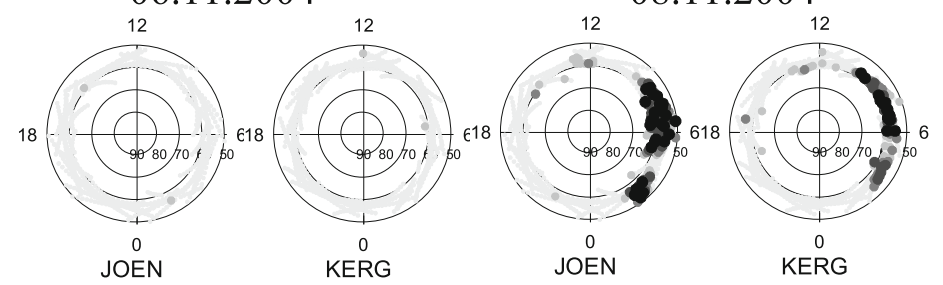

Fig. 10. Location of TEC fluctuations derived from GPS measurements in geomagnetic local time for July and November 2004 storms. The intensity of fluctuations is indicated with the following symbols: $0.5-1.0 \mathrm{TECU} / \mathrm{min}$ - white, $1.5-2.0 \mathrm{TECU} / \mathrm{min}$ - black. 

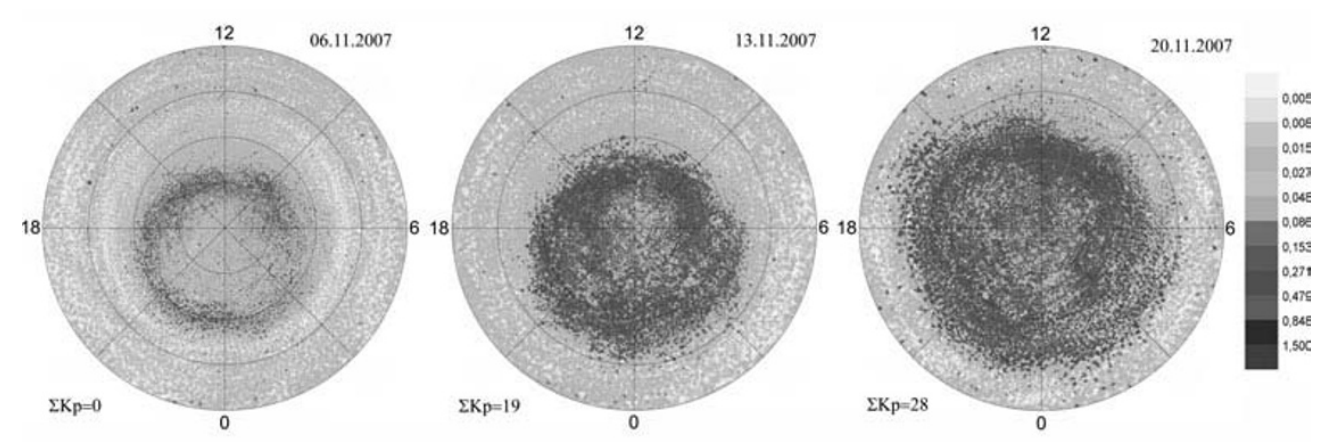

Fig. 11. Maps of the occurrence of TEC fluctuations (ROTI) as a function of MLT and CGM latitude demonstrates the dynamics of the irregularity oval for quiet and disturbed geomagnetic conditions.

oval irregularity, as a function of MLT and CGL, have been formed.

Figure 11 illustrates the spatial-temporal structure and intensity of the ionospheric irregularities for the quiet days and two disturbed days of November 13 and 20, 2007. In the plots (natural logarithm) of the ROTI index derived using GPS observations from all GPS stations mentioned above over a 24-hour period as a function of CGL and GLT is presented. For all stations the time is the geomagnetic local time.

For quiet days $\left(K_{\mathrm{p}} \approx 0\right)$ one can clearly see the irregularity oval which is similar to the auroral oval. The equatorial edge of the oval is located at lower latitudes during local magnetic midnight than at noon (about $10^{\circ}$ ). The occurrence of the irregularities strongly depended on the geomagnetic activity. Even during the moderate disturbances on November 13 (maximum $K_{\mathrm{p}} \sim 03$ ) the irregularity oval sharply expanded and moved equatorward relative to a quiet day. When the $K_{\mathrm{p}}$ index reached a value of about 5 , the irregularities were observed over almost all the high-latitude (>60 degrees) ionosphere.

\section{Conclusion}

GPS measurements of Northern and Southern hemispheres were used to study storm-time developments of TEC fluctuations at conjugate areas in the polar, auroral and subauroral ionosphere. During geomagnetic storms, the intensity of the irregularities essentially increases and their location expands towards the equator. This supports the conclusions obtained recently by Spogli et al. (2009). Maximum activity of the TEC fluctuations took place when the IMF $B_{z}$ component was negative. An increasing TEC fluctuation activity can be also observed under high positive $B_{z}$ values. The storm-time development of TEC fluctuations caused by ionospheric irregularities was controlled by UT. At the polar stations, TEC fluctuations are more expressed in the winter hemisphere. Over the auroral stations, the difference of TEC fluctuation occurrence was less expressed. During the storms, strong TEC fluctuations can be observed at the subauroral ionosphere (latitudes lower than 55 CGL). A seasonal effect in this area is also observed.

The spatial distribution of TEC fluctuations form the irregularity oval. It has been shown that a GPS technique can be effectively used for probing the irregularity oval of the high-latitude ionosphere. The dynamics of the irregularity oval is controlled by geomagnetic activity. During storms, the intensity of the irregularities essentially increases and the oval expands towards the equator.

Acknowledgments. We wish to acknowledge the International GNSS Service (IGS) for providing the GPS Data.

\section{References}

Aarons, J., Global positioning system phase fluctuations at auroral latitudes, J. Geophys. Res., 102(A8), 17219-17231, 1997.

Forte, B. and S. Radicella, Geometrical control of scintillation indices: What happens for GPS satellites, Radio Sci., 39, RS5014, doi:10.1029/2002RS002852, 2004.

Jakowski, N., S. M. Stankov, and D. Klaehn, Operational space weather service for GNSS precise positioning, Ann. Geophys., 23, 3071-3079, 2005.

Krankowski, A., I. Shagimuratov, L. Baran, and I. Ephishov, Study of TEC fluctuations in Antarctic ionosphere during storm using GPS observations, Acta Geophys. Pol., 53(2), 205-218, 2005.

Pedersen, T. R., B. G. Fejer, R. A. Doe, and E. J. Weber, An incoherent scatter radar technique for determining two-dimensional horizontal ionization structure in polar cap F region patches, J. Geophys. Res., 105(A5), 10637-10655, 2000.

Pi, X., A. J. Manucci, U. J. Lindqwister, and C. M. Ho, Monitoring of global ionospheric irregularities using the worldwide GPS network, Geophys. Res. Lett., 24, 2283-2286, 1997.

Rama Rao, P. V. S., S. Gopi, Krishna, J. Vara Prasad, S. N. V. S. Prasad, D. S. V. V. D. Prasad, and K. Niranjan, Geomagnetic storm effect on GPS based navigation, Ann. Geophys., 27, 2101-2110, 2009.

Rodger, A. S. and T. J. Rosenberg, Riometer and HF radar signatures of polar patches, Radio Sci., 34(2), 501-508, 1999.

Shagimuratov, I. I., I. I. Ephishov, and N. Yu. Tepenitsyna, Similarities and differences of storm time occurrence of GPS phase fluctuations at northern and southern hemispheres, in Proceeding EUCap, 2009.

Spogli, L., L. Alfonsi, G. De Franceschi, V. Romano, M. H. O. Aquino, and A. Dodson, Climatology of GPS ionospheric scintillation over high and mid-latitude European regions, Ann. Geophys., 27, 3429-3437, 2009.

Stankov, S. M. and N. Jakowski, Ionospheric effects on GNSS reference network integrity, J. Atmos. Sol.-Terr. Phys., 69, 485-499, 2007.

Wanninger, L., Monitoring ionospheric disturbances using IGS Network, in IGS Workshop Proceedings, Special Topics and New Direction, Potsdam, 1995.

Weber, E. J., J. Buchau, J. G. Moore, J. R. Sharber, R. C. Livingston, J. D. Winningham, and B. W. Reinisch, F layer ionization patches in the polar cap, J. Geophys. Res., 89, 1683-1694, 1984.

Weber, E. J., J. A. Klobuchar, J. Buchau, H. C. Carlson Jr., R. C. Livingston, O. de la Beaujardiere, M. McReady, and O. J. Bishop, Polar cap F layer patches: Structure and dynamics, J. Geophys. Res., 91, 12121, 1986.

Wielgosz, P., I. Kashani, and D. A. Grejner-Brzezinska, Analysis of longrange network RTK during severe ionospheric storm, J. Geod., 79(9), 524-531, 2005.

I. I. Shagimuratov, A. Krankowski (e-mail: kand@uwm.edu.pl), I. Ephishov, Yu. Cherniak, P. Wielgosz, and I. Zakharenkova 